\title{
24-Hour ICH Score Is a Better Predictor of Outcome than Admission ICH Score
}

\author{
Aimee M. Aysenne, ${ }^{1,2}$ Karen C. Albright, ${ }^{3,4,5}$ Tiffany Mathias, ${ }^{1}$ Tiffany R. Chang, ${ }^{1,6}$ \\ Amelia K. Boehme, ${ }^{5,7}$ T. Mark Beasley, ${ }^{8}$ and Sheryl Martin-Schild ${ }^{1}$ \\ ${ }^{1}$ Stroke Program, Department of Neurology, Tulane University Hospital, 1440 Canal Street, TB-52, Suite 1000, New Orleans, \\ LA 70112-2715, USA \\ ${ }^{2}$ Neurovascular Service and Neurocritical Care, Department of Neurology, University of California, San Francisco, CA 94143, USA \\ ${ }^{3}$ Health Services and Outcomes Research Center for Outcome and Effectiveness Research and Education (COERE), \\ University of Alabama at Birmingham, Birmingham, AL 35249, USA \\ ${ }^{4}$ Center of Excellence in Comparative Effectiveness Research for Eliminating Disparities (CERED), \\ Minority Health \& Health Disparities Research Center (MHRC), University of Alabama at Birmingham, \\ Birmingham, AL 35249, USA \\ ${ }^{5}$ School of Public Health, Department of Epidemiology, University of Alabama at Birmingham, Birmingham, AL 35249, USA \\ ${ }^{6}$ Division of Neurosciences Critical Care, Department of Anesthesia Critical Care Medicine, Johns Hopkins University, \\ Baltimore, MD 21287, USA \\ ${ }^{7}$ School of Medicine, Department of Neurology, University of Alabama at Birmingham, Birmingham, AL 35249, USA \\ ${ }^{8}$ Department of Biostatistics, School of Public Health, University of Alabama at Birmingham, Birmingham, AL 35294, USA
}

Correspondence should be addressed to Sheryl Martin-Schild; smartinschild@gmail.com

Received 19 August 2013; Accepted 8 September 2013

Academic Editors: D. Dowlatshahi, A. Ducruet, and P. A. Nyquist

Copyright (C) 2013 Aimee M. Aysenne et al. This is an open access article distributed under the Creative Commons Attribution License, which permits unrestricted use, distribution, and reproduction in any medium, provided the original work is properly cited.

Background. The ICH score is a validated tool for predicting 30-day morbidity and mortality in patients with intracerebral hemorrhage. Aims and/or Hypothesis. The aim of this study is to determine if the ICH score calculated 24 hours after admission is a better predictor of mortality than the ICH score calculated on admission. Methods. Patients presenting to our center with ICH from 7/08-12/10 were retrospectively identified from our prospective stroke registry. ICH scores were calculated based on initial Glasgow coma scale (GCS) and emergent head computed tomography (CT) on initial presentation and were recalculated after 24 hours. Results. A total of 91 patients out of 121 had complete data for admission and 24-hour ICH score. The ICH score changed in $38 \%$ from baseline to 24 hours. After adjusting for age, NIHSS on admission, and glucose, ICH score at 24 hours was a significant, independent predictor of mortality $(\mathrm{OR}=2.71,95 \% \mathrm{CI} 1-19-6.20$, and $P=0.018)$, but $\mathrm{ICH}$ score on admission was not $(\mathrm{OR}=$ $2.14,95 \%$ CI $0.88-5.24$, and $P=0.095)$. Conclusion. Early determination of the ICH score may incorrectly estimate the severity and expected outcome after ICH. Calculations of the ICH score 24 hours after admission will better predict early outcomes.

\section{Introduction}

The intracerebral hemorrhage (ICH) score was developed as a predictive tool for mortality at thirty days after hemorrhagic stroke [1]. The ICH score is a 6-point calculation based on five clinical indicators: age $>80$ years, Glasgow coma scale (GCS), volume of hematoma on baseline CT scan, location (infratentorial or supratentorial), and the presence of intraventricular extension. The ICH score has also been validated for 30-day and one-year functional outcome in additional studies $[2,3]$. In these studies the GCS was measured at the time of admission to the intensive care unit (ICU) or to the operating room regardless of the time of onset of symptoms.

Almost $40 \%$ of patients with brain imaging obtained in the first 3 hours after onset of symptoms of ICH experience hematoma expansion and this is highly associated with neurological deterioration [4]. Recent studies show a strong association between contrast extravasation on computed tomography angiography (CTA) and hematoma expansion and worse outcome [5]. 


\section{Aims and/or Hypothesis}

We hypothesize that, due to the dynamic nature of early $\mathrm{ICH}$, with high risk of hematoma expansion, new IVH, and decreasing level of consciousness, a delayed measure of the ICH score would be more useful in predicting outcomes. In our center, the ICH score is calculated once all five clinical indicators are available, which is typical at the time when the baseline CT is performed, rather than when the patient went to the OR or neurological intensive care unit (ICU). We sought to determine the reliability of the ICH score calculated in the first hour of arrival compared to the reliability of the ICH score calculated 24 hours later.

\section{Methods}

A retrospective chart review of all patients admitted with $\mathrm{ICH}$ from July 2008 to December 2010 was performed. Patients included in this study were spontaneous, nontraumatic ICH with no structural underlying defect. Patients without the variables needed to calculate the admission and 24-hour ICH scores were excluded. ICH volume was calculated using the previously published $\mathrm{ABC} / 2$ method [6-8]. Initial $\mathrm{ICH}$ scores were calculated based on admission head CT and GCS on presentation to the hospital. Repeat ICH scores were calculated using follow-up imaging and GCS within 24 \pm 1 hours of admission [1]. We compared outcomes using admission ICH score versus 24-hour ICH score. Our primary outcome of interest was poor functional outcome (mRS 56 ) at the time of hospital discharge. Our secondary outcome of interest was all-cause in-hospital mortality. Crude and adjusted logistic regression models were used to assess poor functional outcome and mortality using admission ICH score and 24-hour ICH score as predictors. The adjusted logistic regression models accounted for covariates previously shown to be confounders (age, NIHSS on admission, and glucose).

\section{Results}

Of the 119 patients who were eligible, 89 met inclusion criteria. Fourteen patients had mild stroke or had subacute presentations (median baseline ICH score 0 ) and were either not monitored in the neurological ICU or with routine follow-up CT. Fifteen patients had catastrophic stroke and either died prior to 24 hours or did not have follow-up CT (median baseline ICH score 3 ) within the specified timeframe. One patient was in the OR for evacuation and did not have GCS available during the specified timeframe. Table 1 provides a synopsis of the baseline demographics of the patients included in this study.

While the initial ICH score ranged from 0 to 3 (median 1 ), the 24-hour ICH score ranged from 0 to 5 (median 1). On admission, 21 (23.5\%) patients had an ICH score of 0, $33(37 \%)$ patients had an ICH score of $1,19(21.3 \%)$ patients had an ICH score of 2 , and $16(18 \%)$ patients had an ICH score of 3 . No patients included in this study had an admission ICH score of 4,5 , or 6 .

The distribution of ICH scores and frequencies of worsened, improved, or unchanged ICH score at 24 hours are presented in Table 2. Thirty-six percent of patients with $\mathrm{ICH}$ score of 1 on admission worsened on the 24-hour score while
TABLE 1: Demographics information.

\begin{tabular}{|c|c|}
\hline & $N=89$ \\
\hline Age, mean (sd) & $58.07(1.4)$ \\
\hline Male, $\%$ & $46(51.7 \%)$ \\
\hline Black, \% & $67(75.3 \%)$ \\
\hline History of HTN, \% & $71(79.8 \%)$ \\
\hline Antihypertensive medications, $\%$ & $44(49.4 \%)$ \\
\hline On antithrombotics (AP/AC), \% & $32(36 \%)$ \\
\hline History of chronic daily alcohol use, $\%$ & $23(25.8 \%)$ \\
\hline Positive urine tox screen, $\%$ & $17(19.1 \%)$ \\
\hline ICH score on admission, median & $1(0-3)$ \\
\hline Presenting GCS, median & $14(4-15)$ \\
\hline First SBP, mean (sd) & $189.7(3.7)$ \\
\hline First DBP, mean (sd) & $111.2(2.6)$ \\
\hline Baseline NIHSS, median (range) & $15(0-40)$ \\
\hline Glucose on admission, mean (sd) & $144.65(6.7)$ \\
\hline \multicolumn{2}{|l|}{ ICH location } \\
\hline Basal ganglia & $41(46.1 \%)$ \\
\hline Thalamus & $18(20.2 \%)$ \\
\hline Pons & $5(5.6 \%)$ \\
\hline Cerebellum & $5(5.6 \%)$ \\
\hline Lobar & $18(20.2 \%)$ \\
\hline Other & $1(1.1 \%)$ \\
\hline \multicolumn{2}{|l|}{ ICH tentorial location } \\
\hline Supratentorial & $77(86.5 \%)$ \\
\hline Infratentorial & $11(12.4 \%)$ \\
\hline Total & $88(98.9 \%)$ \\
\hline $\mathrm{IVH}, \%$ & $42(47.2 \%)$ \\
\hline Hydrocephalus, \% & $35(39.3 \%)$ \\
\hline Edema on initial HCT, \% & $62(69.7 \%)$ \\
\hline Spot sign on CTA, \% & $10(11.2 \%)$ \\
\hline Dot sign present on CTA, \% & $16(18 \%)$ \\
\hline New IVH, \% & $6(6.7 \%)$ \\
\hline ICH expansion, \% & $42(47.2 \%)$ \\
\hline Evacuation, \% & $12(13.5 \%)$ \\
\hline EVD placed, $\%$ & $28(31.5 \%)$ \\
\hline Did patient receive vitamin $\mathrm{k} ? \%$ & $10(11.2 \%)$ \\
\hline Did patient receive FFP? \% & $14(15.7 \%)$ \\
\hline Did patient receive platelets? \% & $17(19.1 \%)$ \\
\hline Did patient receive NOVO7? \% & $4(4.5 \%)$ \\
\hline IVtPA, \% & $5(5.6 \%)$ \\
\hline In-hospital infection, $\%$ & $33(37.1 \%)$ \\
\hline In-hospital DVT, \% & $2(2.2 \%)$ \\
\hline In-hospital UTI, \% & $24(27 \%)$ \\
\hline In-hospital bacteremia, $\%$ & $12(13.5 \%)$ \\
\hline Best 24 hr GCS, median & $13(3-15)$ \\
\hline Follow-up volume, median (range) & $12.3(0-402)$ \\
\hline 24-hour ICH score, median & $1.0(0-5)$ \\
\hline Transfer patient, $\%$ & $8(9 \%)$ \\
\hline Initial shift on HCT, median (range) & $2.0(0-17)$ \\
\hline ICH initial volume, median (range) & $12.8(0-186)$ \\
\hline ICH volume $24 \mathrm{hrs}$, median (range) & $11(0-402)$ \\
\hline ICH volume growth in $24 \mathrm{hrs,} \mathrm{median} \mathrm{(range)}$ & $0(-107-346)$ \\
\hline Length of stay, median (range) & $10(2-86)$ \\
\hline mRS on discharge, median (range) & $4(1-6)$ \\
\hline Death, \% & $14(15.7 \%)$ \\
\hline
\end{tabular}


TABLE 2: Baseline ICH score stratified by 24-hour ICH score status.

\begin{tabular}{|c|c|c|c|c|c|}
\hline ICH score & $\begin{array}{l}\text { ICH score of } 0 \\
\quad(N=21)\end{array}$ & $\begin{array}{l}\text { ICH score of } 1 \\
\quad(N=33)\end{array}$ & $\begin{array}{l}\text { ICH score of } 2 \\
(N=19)\end{array}$ & $\begin{array}{l}\text { ICH score of } 3 \\
\quad(N=16)\end{array}$ & $P$ value ${ }^{*}$ \\
\hline Number of patients whose ICH score worsened & $3(14.3 \%)$ & $12(36.4 \%)$ & $3(15.8 \%)$ & $2(12.5 \%)$ & 0.118 \\
\hline Number of patients whose ICH score remained the same & $18(85.7 \%)$ & $18(54.5 \%)$ & $11(57.9 \%)$ & $8(50.0 \%)$ & 0.076 \\
\hline Number of patients whose ICH score improved & 0 & $3(9.1 \%)$ & $5(26.3 \%)$ & $6(37.5 \%)$ & 0.006 \\
\hline
\end{tabular}

${ }^{*} P$ value for comparison of each row.

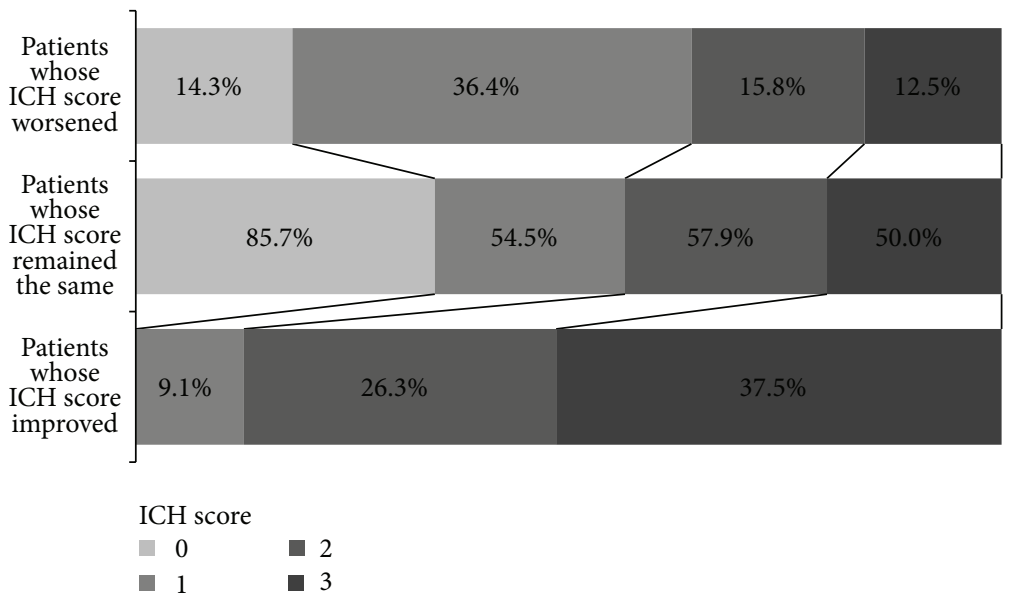

FIGURE 1: Differences in admission and 24-hour ICH score.

$38 \%$ of patients with ICH score of 3 on admission improved on the 24-hour score. The ICH score changed in the first 24 hours for $38 \%$ of patients with spontaneous ICH (Figure 1).

In the crude model, the odds ratio for poor functional outcome $(\mathrm{OR}=5.975,95 \% \mathrm{CI}$, and $P<0.0001)$ and death $(\mathrm{OR}=3.562,95 \% \mathrm{CI}$, and $P<0.0001)$ based on the 24 -hour $\mathrm{ICH}$ score were greater than the admission ICH score odds ratios for both poor functional outcome $(\mathrm{OR}=3.369,95 \%$ $\mathrm{CI}$, and $P<0.001)$ and death $(\mathrm{OR}=2.933,95 \% \mathrm{CI}$, and $P=$ 0.001). After adjusting for age, baseline NIHSS, and admission glucose, baseline ICH score was not an independent predictor of poor functional outcome $(\mathrm{OR}=1.904,95 \% \mathrm{CI}$ $0.937-3.869$, and $P=0.075)$ or death (OR $=1.580,95 \% \mathrm{CI}$ $0.684-3.649$, and $P=0.284$ ). In the adjusted model, 24 -hour ICH score was an independent predictor of poor functional outcome $(\mathrm{OR}=4.672,95 \% \mathrm{CI} 1.996-10.939$, and $P<0.0001)$ and death $(\mathrm{OR}=2.712,95 \% \mathrm{CI} 1.187-6.195$, and $P=0.018)$ (Table 3 ). It was a worsening in the GCS that resulted in worsening in ICH score at 24 hours in most cases $(n=14)$, followed by volume category increase $(n=5)$ and development of IVH $(n=3)$. Similarly, among patients with improved ICH score at 24 hours, the GCS improved in the majority of cases $(n=8)$ and volume reduced after evacuation in the others $(n=4)$.

\section{Discussion}

Our study found that 24-hour ICH score was better predictor of short-term functional outcome and mortality than initial ICH score. More than one-third of patients had a shif in the $\mathrm{ICH}$ score at 24 hours with similar proportions of patients
TABLE 3: Logistic regression models.

\begin{tabular}{lccc}
\hline & OR & $95 \%$ CI & $P$ value \\
\hline $\begin{array}{l}\text { Crude model predicting death } \\
\quad \text { Admission ICH score }\end{array}$ & 2.933 & $1.510-5.699$ & 0.001 \\
$\quad$ 24-hour ICH score & 3.562 & $1.754-7.233$ & $<0.0001$ \\
$\begin{array}{l}\text { Crude model predicting poor mRS } \\
\text { (5-6) }\end{array}$ & & & \\
$\quad$ Admission ICH score & 3.369 & $1.934-5.869$ & $<0.001$ \\
$\quad$ 24-hour ICH score & 5.975 & $2.812-12.696$ & $<0.0001$ \\
$\begin{array}{l}\text { Adjusted model predicting death } \\
\quad\end{array}$ & 1.580 & $0.684-3.649$ & 0.284 \\
$\quad \begin{array}{l}\text { Admission ICH score } \\
\text { 24-hour ICH score }\end{array}$ & 2.712 & $1.187-6.195$ & 0.018 \\
$\begin{array}{l}\text { Adjusted model predicting poor } \\
\text { mRS (5-6) }\end{array}$ & & & \\
$\quad \begin{array}{llll}\text { Admission ICH score } \\
\text { 24-hour ICH score }\end{array}$ & 1.904 & $0.937-3.869$ & 0.075 \\
\hline
\end{tabular}

${ }^{*}$ Adjusting for age, baseline NIHSS, and glucose on admission.

with low scores worsening and high scores improving, mostly related to changes in GCS category. Although the ICH score was shown to be predictive of outcome, the exact time the ICH scores were calculated from the time of symptom onset is not known. Given that components of the ICH score are dynamic soon after ICH onset, particularly with hematoma expansion or interventions and procedures actively changing ICH volume, GCS, and IVH, the utility of using a predictive scoring system at 24-hours instead of on admission to predict 
outcomes increases the predictive value of the scoring system. The 24 hour ICH score is more precise. During this hyperacute phase, the ICH score on admission may underestimate the severity of the stroke since an ICH score can change rapidly due to decline in GCS or hematoma expansion. Likewise, early interventional therapies may improve the score with hematoma evacuation, hemicraniectomy, and appropriate management of intracranial pressure or intraventricular tissue plasminogen activator. Our data supports that early prognostication of outcomes should be avoided when possible, and using an ICH score calculated at a later time during the ICH admission is a better indicator of patient outcomes, after the hematoma has been stabilized and definitive therapies have been provided.

These findings further support how crucial the treatment of a patient within the first few hours after development of $\mathrm{ICH}$ is, particularly for interventions focused on prevention of hematoma expansion by blood pressure control, consideration of hemostatic agents and evacuation of hematoma or hemicraniectomy when appropriate, and prevention of complications such as aspiration. The ICH score is not a predictor of the outcome of an individual patient but a populationbased guide that can aid in predicting the potential outcomes for ICH patients. These results provide continued evidence that treating physicians should remain vigilant with patient care for the $\mathrm{ICH}$ patient and provide aggressive measures until the course is declared.

Our study was limited by small sample size and our ability to adjust for other factors, such as blood pressure control and interventional procedures, both of which could affect the outcome. Evaluation of patients with more severe hemorrhages (ICH scores of 4, 5, and 6) was not possible due to unavailable data including follow-up ICH volume and/or GCS, raising the question of a self-fulfilling prophecy with early withdrawal of aggressive measures. This is, however, a study of early evolution of ICH score among patients with a reasonable chance of survival. It is possible that some patients with baseline ICH scores of 4 or 5 could be converted to lesser ICH scores, but we were unable to assess this in our population due to the information not being available. Further investigation in a larger sample is needed to validate our findings. A prospective study of the impact of time from symptom onset to calculation of the ICH score may be warranted to determine when, after $\mathrm{ICH}$, the ICH score becomes reliable.

\section{Disclosure}

The project described was supported by Awards nos. 5 T32 HS013852-10 from The Agency for Healthcare Research and Quality (AHRQ), 3 P60 MD000502-08S1 from The National Institute on Minority Health and Health Disparities (NIMHD), National Institutes of Health (NIH), and 13PRE13830003 from the American Heart Association. The content is solely the responsibility of the authors and does not necessarily represent the official views of the AHRQ, AHA, or the NIH.

\section{References}

[1] J. C. Hemphill, D. C. Bonovich, L. Besmertis, G. T. Manley, and S. C. Johnston, "The ICH score: a simple, reliable grading scale for intracerebral hemorrhage," Stroke, vol. 32, no. 4, pp. 891-897, 2001.

[2] J. C. Hemphill, M. Farrant, and T. A. Neill Jr., "Prospective validation of the ICH Score for 12-month functional outcome," Neurology, vol. 73, no. 14, pp. 1088-1094, 2009.

[3] C. Weimar, A. Ziegler, R. L. Sacco, H. C. Diener, and I. R. König, "Predicting recovery after intracerebral hemorrhage-an external validation in patients from controlled clinical trials," Journal of Neurology, vol. 256, no. 3, pp. 464-469, 2009.

[4] T. Brott, J. Broderick, R. Kothari et al., "Early hemorrhage growth in patients with intracerebral hemorrhage," Stroke, vol. 28, no. 1, pp. 1-5, 1997.

[5] J. E. D. Almandoz, A. J. Yoo, M. J. Stone et al., "The spot sign score in primary intracerebral hemorrhage identifies patients at highest risk of in-hospital mortality and poor outcome among survivors," Stroke, vol. 41, no. 1, pp. 54-60, 2010.

[6] A. Tada, K. Hisada, T. Suzuki, and S. Kadoya, "Measurement volume of intracranial hematoma by computed tomography (author's translation)," No Shinkei Geka, vol. 9, no. 3, pp. 251256, 1981.

[7] R. Kwak, S. Kadoya, and T. Suzuki, "Factors affecting the prognosis in thalamic hemorrage," Stroke, vol. 14, no. 4, pp. 493-500, 1983.

[8] R. U. Kothari, T. Brott, J. P. Broderick et al., "The ABCs of measuring intracerebral hemorrhage volumes," Stroke, vol. 27, no. 8, pp. 1304-1305, 1996. 


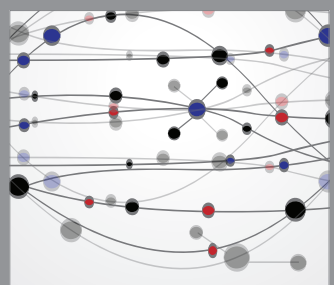

The Scientific World Journal
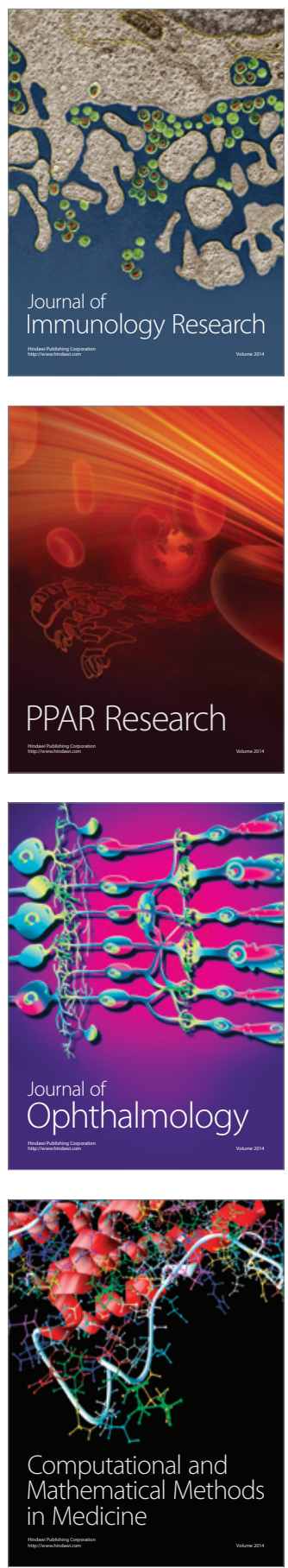

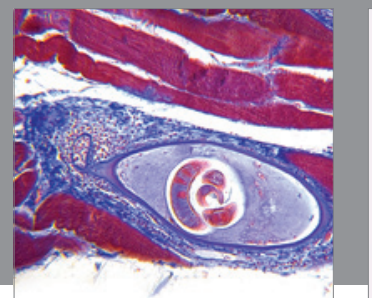

Gastroenterology

Research and Practice
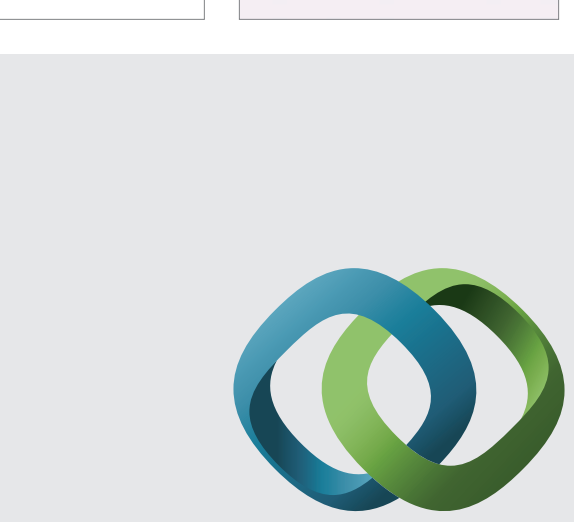

\section{Hindawi}

Submit your manuscripts at

http://www.hindawi.com
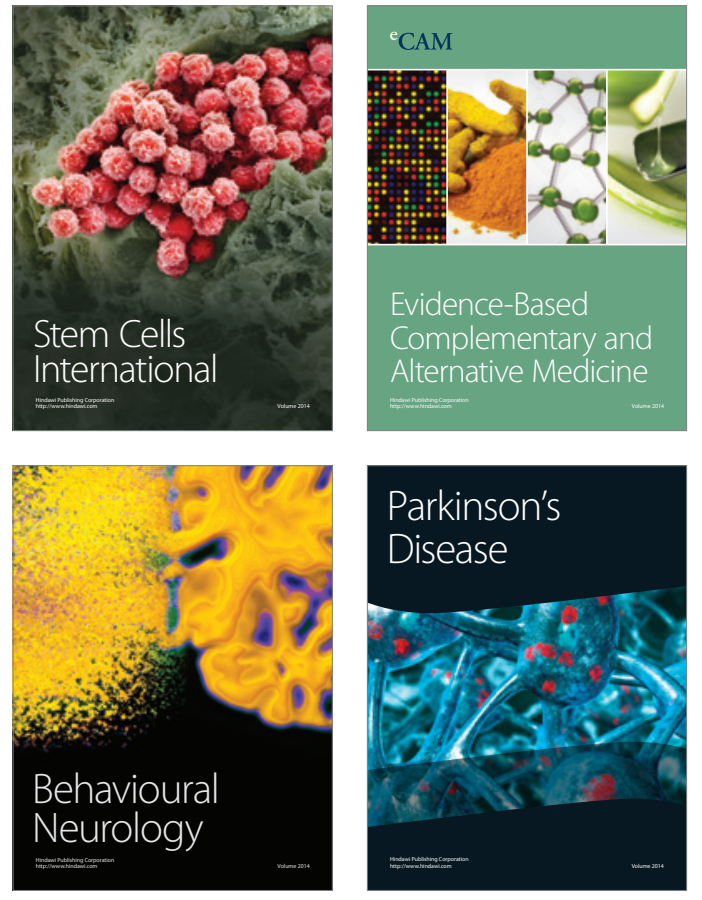
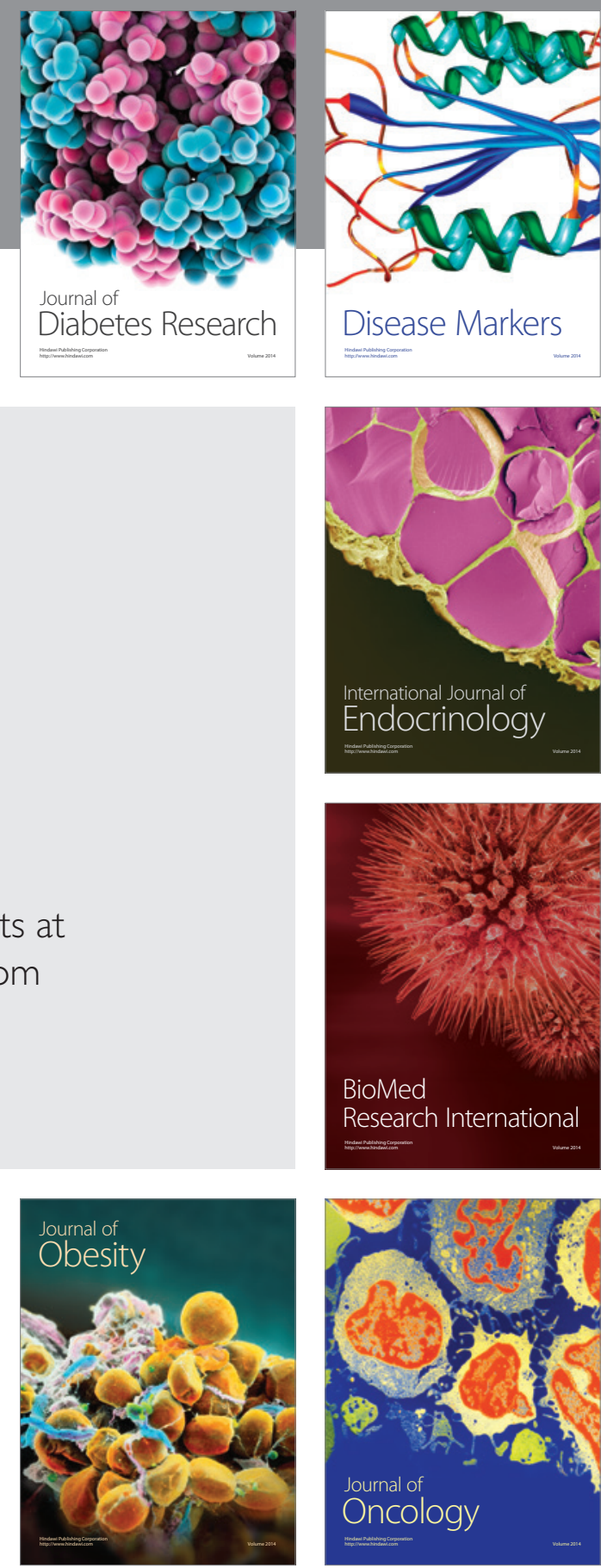

Disease Markers
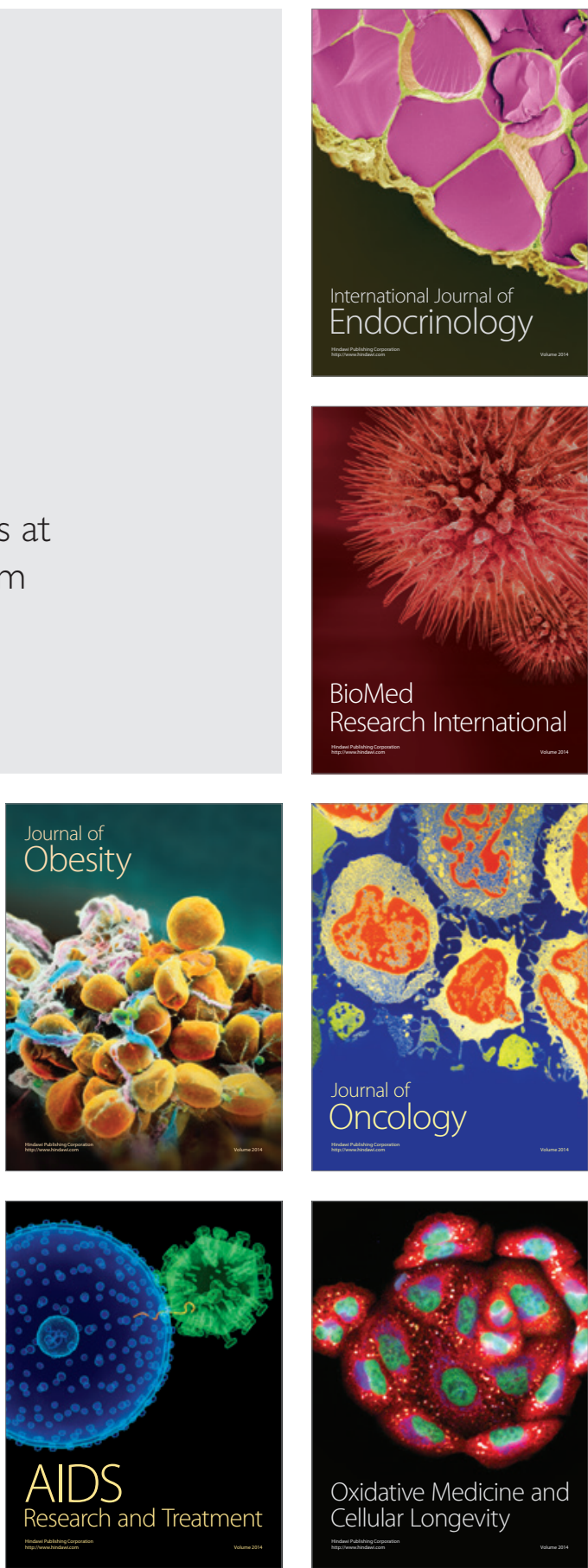